\title{
Como ensinar frações? Práticas que (in)formam o professor que ensina matemática
}

\author{
How to teach fractions? Practices that (in)form teachers teaching \\ mathematics
}

\section{¿Cómo enseñar fracciones? Prácticas que (in)forman el profesor que enseña matemática}

\author{
Marta Cristina Cezar Pozzobon' \\ Universidade Federal do Pampa (Unipampa), Professora no Curso de Pedagogia e no \\ Programa de Pós-Graduação em Educação
}

Cláudio José de Oliveira ${ }^{2}$

Universidade de Santa Cruz do Sul, Professor no Programa de Pós-Graduação em Educação

Resumo: Neste artigo discute-se sobre a formação do professor que ensina matemática nos anos iniciais, em especial no que se refere ao ensino de frações. O corpus de análise selecionado para este texto se constitui do caderno de matemática de um programa de formação continuada de professores dos anos iniciais do Ensino Fundamental, de uma entrevista com uma professora de Didática da Matemática que atuou na formação de professores na década de 1970 e de seu caderno de planejamento. Para realizar as análises, adotamos uma perspectiva teórica pós-crítica associada aos estudos de Ludwig Wittgenstein. $\bigcirc$ que defendemos é que os conceitos são produzidos a partir dos usos, em conformidade com suas regras gramaticais, e que os significados de uma palavra e os significados das proposições matemáticas são produzidos nos diferentes jogos de linguagem. Das análises empreendidas no material, foram organizados dois enunciados: a) Ensinar frações: "trazer um bolo" e "fazer um desenho" e b) "Lembrar seu significado" para ensinar o conceito de frações. A partir desses enunciados, problematizamos que os conceitos matemáticos são normas que independem do cotidiano e de aspectos empíricos, intuitivos ou indutivos. Desse modo, sugerimos que o professor tenha conhecimento da natureza das proposições matemáticas e se responsabilize pelo ensino de suas

Doutora em Educação pela Universidade do Vale do Rio dos Sinos (Unisinos); Mestre em Educação pela Universidade Regional do Noroeste do Estado do Rio Grande do Sul (Unijuí).

2 Doutor e Mestre em Educação pela Universidade do Vale do Rio dos Sinos (Unisinos). 
regras, não trazendo a utilidade dos conceitos, mas as convenções produzidas pela linguagem matemática.

Palavras-chave: Ensino de frações. Anos iniciais. Educação Matemática. Práticas.

Abstract: This article discusses the formation of the teacher who teaches mathematics in the initial years, especially in what concerns the teaching of fractions. The corpus of analysis selected for this text consists of the mathematics notebook of the continuing education program for teachers of the early years of Elementary School, an interview and a planning notebook of a Mathematics Didactics teacher who acted in the formation of teachers during the 1970s. In order to carry out the analyzes, we adopted a post-critical theoretical perspective associated with the studies of Ludwig Wittgenstein. What we defend is that concepts are produced from the uses, in accordance with their grammatical rules, and that the meanings of a word and the meanings of the mathematical propositions are produced in the different language games. From the analyzes undertaken in the material, two statements were organized: a) Teach fractions: "bring a cake" and "make a drawing" and b) "Remember its meaning" to teach the concept of fractions. From these statements, we problematize that the mathematical concepts are norms that are independent of the quotidian and of empirical, intuitive or inductive aspects. In this way, we suggest that the teacher be aware of the nature of mathematical propositions and be responsible for the teaching of their rules, not bringing the usefulness of the concepts, but the conventions produced by the mathematical language.

Keywords: Teaching of fractions. Early years. Mathematical education. Practices.

Resumen: Este artículo discute la formación del profesor que enseña matemáticas en los años iniciales, en especial, en lo que se refiere a la enseñanza de fracciones. El corpus de análisis seleccionado para este texto se constituye del cuaderno de matemáticas del programa de formación continuada de profesores de los años iniciales de la Enseñanza Fundamental, de una entrevista y de un cuaderno de planificación de una profesora de Didáctica de la Matemática, que actuó en la formación de profesores en la década de 1970. Para realizar los análisis, adoptamos una perspectiva teórica post-crítica asociada a los estudios de Ludwig Wittgenstein. Lo que defendemos es que los conceptos son producidos a partir de 
los usos, de acuerdo con sus reglas gramaticales, y que los significados de una palabra y los significados de las proposiciones matemáticas son producidos en los diferentes juegos de lenguaje. De los análisis emprendidos en el material se organizaron dos enunciados: a) Enseñar fracciones: "traer un pastel" y "hacer un dibujo" y b) "Recordar su significado" para enseñar el concepto de fracciones. A partir de estos enunciados, problematizamos que los conceptos matemáticos son normas que independen de lo cotidiano y de aspectos empíricos, intuitivos o inductivos. De este modo, sugerimos que el profesor tenga conocimiento de la naturaleza de las proposiciones matemáticas y se responsabilice por la enseñanza de sus reglas, no trayendo la utilidad de los conceptos, sino las convenciones producidas por el lenguaje matemático.

Palabras clave: Enseñanza de fracciones. Años iniciales. Educaciones Matemáticas. Prácticas.

\section{INTRODUÇÃO}

Neste artigo discute-se sobre a formação do professor que ensina matemática nos anos iniciais, em especial no que se refere ao ensino de frações. No texto apresentam-se e discutem-se os resultados de uma pesquisa concluída recentemente. Neste artigo, o corpus de análise se constitui de três documentos: o primeiro é um caderno de planejamento de uma professora de Didática da Matemática da década de 1970 que atuou na formação de professores em nível médio; o segundo é o caderno Pró-Letramento: Programa de Formação Continuada de Professores dos Anos/Séries Iniciais do Ensino Fundamental: matemática (BRASIL, 2007); e o último, uma entrevista com a mesma professora.

Para realizar as análises, adotamos uma perspectiva teórica que, segundo Vilela (2013, p. 21, grifo nosso), "[...] se costuma denominar filosofia pós-crítica, marcada pela guinada linguística, associada também ao segundo Wittgenstei." Essa perspectiva concebe a linguagem como produtiva do conhecimento, não havendo interesse pelo que está oculto, como ensina Wittgenstein (1979); a preocupação é com a expressão do conhecimento, com os usos, que podem variar conforme os jogos de linguagem estabelecidos entre os sujeitos nos diferentes contextos. 
$\bigcirc$ que defendemos e o que interessa para esta investigação, com base em Wittgenstein (1978, 1979), é que os conceitos são produzidos a partir dos usos, em conformidade com suas regras gramaticais, e que os significados de uma palavra e os significados das proposições matemáticas são produzidos nos diferentes jogos de linguagem. As contribuições de Gottschalk (2004, 2007, 2008, 2014), principalmente quando diz que existe "[...] conexão entre a atividade de ensinar e a constituição de significados", interessam-nos por esclarecerem que, para Wittgenstein, as proposições matemáticas são entendidas como normas, como princípios de juízos, por isso: "2+2 deve ser igual a 4! Essa proposição não é negada nem confirmada, é apenas uma regra de como proceder (um princípio de juízo)." (GOTTSCHALK, 2008, p. 79). Isso quer dizer que seguimos as proposições matemáticas, as quais têm uma função normativa, que não se referem a nada e que apenas organizam a experiência empírica.

As discussões de Miguel e Vilela (2008) sobre práticas escolares de ensino e aprendizagem de matemática apontam que as perspectivas mnemônico-mecanicistas orientaram a cultura escolar durante o Período Imperial no nosso País e que as empírico-intuitivas começaram a aparecer durante o século XIX e início do século XX nas obras de autores como Comenius, Locke, Pestalozzi, Fröbel e Montessori, os quais "procuraram fundamentar-se em argumentos pedagógicos baseados em uma psicologia empírico-indutivista de cunho associacionista de aprendizagem matemática [...]" (MIGUEL; VILELA, 2008, p. 102). As "chamadas perspectivas construtivistas" começam a mobilizar o ensino da matemática a partir da década de 1970, "reivindicando o papel fundamental da ação e da operação" e enfatizando a ideia de número natural, estágios de desenvolvimento e abstração reflexiva. Como crítica às teorias construtivistas, os autores questionam por que uma pessoa bem-sucedida, que lida com certo tipo de conhecimento em uma prática social, apresentaria dificuldade em lidar com esse mesmo conhecimento em outras práticas.

Para essas discussões, Miguel e Vilela (2008) apoiam-se em Wittgenstein e em Lave, no sentido de mostrar que as práticas matemáticas escolares apresentam jogos de linguagem que podem ter semelhanças com outros grupos culturais, como da rua, do comércio e da cozinha. É importante destacar que "[...] o que se aprende na escola não é transferido para as práticas situadas não-escolares, como 
também, inversamente, matemáticas mobilizadas por práticas não-escolares não são transferidas para a escola." (MIGUEL; VILELA, 2008, p. 113).

Lave (2002) argumenta que a aprendizagem (da matemática) como algo inseparável das práticas sociais distintas não se trata de aquisição de um saber, mas de um processo de apropriação das mesmas práticas. A autora afirma que não há como explicar um processo cognitivo matemático sem considerá-lo como um processo vinculado às práticas sociais. Para a autora,

Admitindo-se que a matemática assuma forma universal, capaz de ser transportada para todas as situações e ser executada de modo uniforme, as respostas para essas questões [é válido transportar as descobertas experimentais para atividades desenvolvidas fora do laboratório? [...] Quem deve decidir quais fenômenos cognitivos merecem ser estudados? poderiam ser consideradas simples e poderiam ser simplesmente aceitas. Não haveria dúvida a respeito da validade da extrapolação de descobertas de laboratório para outras situações. Se a prática matemática assume formas específicas de acordo com a situação, isso implica que as propriedades matemáticas formais dos problemas potenciais não são suficientes para verificar quais questões emergirão na prática. (LAVE, 2002, p. 69).

Miguel, Vilela e Moura (2012) discutem as possibilidades de pensarmos as práticas culturais realizando o seu deslocamento por diferentes campos de atividade humana, entre eles o campo da atividade escolar. Para isso, os autores estabelecem relações com alguns aspectos da filosofia de Wittgenstein (1979), principalmente no que desfaz a concepção essencialista de linguagem e no entendimento de que o significado se encontra nos usos que os sujeitos fazem nos grupos de convivência para se tornarem membros de uma comunidade. Para corroborar essa ideia, trazemos que

[...] olhar a matemática em processo [...] permite olhar para as práticas tanto do professor quanto do matemático profissional ou do leigo em situações cotidianas, isto é, matemáticas tais como são mobilizadas por diferentes práticas situadas em diferentes campos de atividade humana. (MIGUEL; VILELA; MOURA, 2012, p. 8-9). 
Esses estudos - e outros - têm nos mobilizado a continuar investigando a formação do professor para ensinar matemática nos anos iniciais, considerando que o conhecimento matemático produz as práticas e os sujeitos pedagógicos, pois estes não existem fora do discurso pedagógico e dos processos que constituem os sujeitos-professores (DÍAZ, 1998). Diante disso, consideramos os caminhos teóricos e metodológicos do estudo; depois, ativemo-nos a analisar o material investigado, organizado em dois enunciados recorrentes na formação do professor de anos iniciais na atualidade. Na última parte, tecemos algumas considerações acerca do estudo realizado.

\section{CAMINHOS TEÓRICOS E METODOLÓGIICOS}

A fim de desenvolver o presente artigo, intencionamos problematizar a formação do professor para o ensino de conceitos matemáticos, especificamente o conceito de fração. Para isso, destacamos as ideias de Foucault (2010) sobre "práticas de formação", que envolvem as práticas de poder, as práticas governamentais, que tratam de colocar em questão o sujeito do conhecimento, a arte de governar os outros e a si mesmo. O autor lembra que é em certo número de práticas que somos convidados a nos tornar sujeitos, a dizer a verdade sobre nós mesmos, a aceitar os discursos produzidos por essas práticas. Então, as práticas de formação são "um conjunto de discursos [...] que constituem, fabricam, tanto os objetos quanto os sujeitos com o objetivo de formar, ensinar e governar no sentido de tornarem-se professores contemporâneos." (FABRIS, 2012, p. 9).

Diante disso, a preocupação é problematizar o ensino do conceito de fração, que foi e é recorrente para a formação do professor de anos iniciais. Para tanto, consideramos uma entrevista com uma professora de Didática da Matemática que atuou na formação de professores na década de 1970, o caderno Pró-Letramento: Programa de Formação Continuada de Professores dos Anos/Séries Iniciais do Ensino Fundamental: matemática e seu caderno de planejamento. Com isso, quisemos tencionar a ideia de um modo "correto" de ensinar fração, que perpassa a formação dos professores que ensinam matemática nos anos iniciais do Ensino Fundamental. 
De acordo com Wittgenstein (1979), o significado de uma expressão se dá pelo seu uso na linguagem, nas práticas, dependendo do contexto em que está inserido. "O significado de um conceito matemático empregado na prática, utilizado por um feirante que lida com dinheiro ou com um pedreiro que se ocupa com medidas, recebe conteúdo prático da atividade em questão, que é diferente da atividade do profissional de matemática [...]" (SILVA; SILVEIRA, 2013, p. 127). Assim, argumentamos que os conceitos matemáticos são aprendidos a partir dos seus diversos usos nas práticas linguísticas, e que esses diferentes usos, aplicabilidades e modos de operar com os conceitos permitem ver de outros modos "e, com isso, visa também equilibrar um pouco as imagens exclusivistas alimentadas pelas concepções mais frequentes da matemática." (VILELA, 2013, p. 39). Essas ideias estão na direção do proposto por Moreno (1995, p. 39) ao esclarecer que, ao lidarmos com enunciados matemáticos, não nos referimos a fatos ou essências matemáticas; ao contrário, eles exprimem

[...] nossa atitude (Einstellung) em face a técnicas de cálculo e ao uso que fazemos dos números. Passamos a ver que a necessidade de " $2+2=4$ " é relativa a um sistema de convenções aceitas consensualmente e que essas convenções desempenham papéis importantes na nossa vida: elas permitem, por exemplo, que se espere com certeza a repetição de um mesmo resultado - sem que, para isso, seja preciso postular princípios a priori organizadores da experiência e nem uma crença irracional como fundamento do conhecimento científico.

Essas ideias abandonam as perspectivas que buscam uma essência. Explica-se a natureza do conhecimento matemático ancorando-se as discussões na prática linguística e nos contextos de uso e desmistificando as pretensas perspectivas que concebem a existência de uma matemática superior, em detrimento de outras que seriam subordinadas àquela. Ao olharmos para os usos, aproximamo-nos dos estudos de Wittgenstein (1979), que se desfaz das concepções essencialistas da linguagem ou, como esclarece Gottschalk (2005, p. 5), não se preocupa em questionar a "concepção referencial da linguagem", que traz um "modo exclusivista de se ver as funções de nossa linguagem [...]", 
em que "o significado das palavras seriam as coisas que elas representam." 0 filósofo busca, em uma perspectiva da pragmática filosófica, explicar que

[...] o conceito de cadeira não é construído a partir do conjunto de minhas experiências com cadeiras empíricas, mas são técnicas lingüísticas (que envolvem fragmentos do mundo empírico) que me permitem atribuir significado a essas experiências e, assim, organizar posteriormente a minha experiência de um outro modo. (GOTTSCHALK, 2005, p. 8-9).

No entendimento de Wittgenstein (1979), as palavras adquirem significados nos seus usos, pois cada palavra "designa algo", ou seja, "[a] prendemos o significado das palavras aprendendo a utilizá-las, da mesma forma que aprendemos a jogar xadrez, não pela associação de peças a objetos, mas sim pela aprendizagem de movimentos para tais peças." (GLOCK, 1998, p. 225). Isso significa dizer que é dentro dos jogos de linguagem que as palavras adquirem significados; como nos jogos de tabuleiro, alguns lances serão aceitos, enquanto outros serão rejeitados em razão das regras constitutivas que determinam os "lances" possíveis.

Ao tratarmos do ensino de frações, consideramos que não existe um modelo referencial de linguagem que aborde a consciência como algo privado, em que se pretende que o aluno aprenda o que se passa na mente do professor. Na perspectiva proposta por Wittgenstein (1979) (IF, \$ 150), "quem compreende algo é capaz de fazer certas coisas. [...] compreende o uso de uma palavra é capaz de empregá-la, de ensiná-la a alguém etc." (SILVA, 201 1, p. 45).

Para respondermos aos nossos questionamentos, lemos cuidadosamente o material empírico, separando as partes que tratam do ensino de frações. Em outro momento, consideramos como é enunciado o ensino de frações nos materiais analisados. Para Foucault (2007), não existe nada a ser descoberto, mas existem enunciados que são colocados em funcionamento pelas práticas discursivas e são tratados como verdadeiros. Os discursos são produzidos por um conjunto de enunciados, que estão ligados a um referencial constituído de "[...] leis de possibilidades, de regras de existência para os objetos 
que aí se encontram nomeados, designados ou descritos, para as relações que aí se encontram afirmadas." (FOUCAULT, 2007, p. 103).

Os materiais foram examinados na perspectiva de mostrar como o ensino de frações é narrado, salientando-se apenas as coisas ditas. Selecionamos os materiais que tratavam do ensino de frações, destacando os enunciados tomados em cada discurso e apontados como verdades num espaço e tempo determinados (VEIGA-NETO, 2007).

\section{O ENSINO DE FRAÇÕES: PRÁTICAS DE FORMAÇÃO QUE (IN) FORMAM O PROFESSOR QUE ENSINA MATEMÁTICA}

Os discursos sobre a formação de professores podem ser olhados como uma série de acontecimentos, tal qual trata Foucault (2003, p. 255-256) ao dizer que importa "estabelecer e descrever as relações que esses acontecimentos - que podemos chamar de acontecimentos discursivos - mantêm com outros acontecimentos que pertencem ao sistema econômico, ou ao campo político, ou às instituições." Apontamos que "desde sempre educar é governar", então, é de responsabilidade do professor "apropriar-se de um conjunto de saberes e práticas que, entre outros aspectos, medeiam a relação que cada um estabelece consigo mesmo (self-government) de modo a direcionar sua própria conduta como docente." (COUTINHO; SOMMER, 201 l, p. 98).

A partir dessas considerações, descrevemos dois enunciados para o ensino de frações, que pontuamos nos materiais examinados: "Trazer um bolo" e "fazer um desenho" e "Lembrar seu significado" para aprender o conceito de frações.

\section{1 “TRAZER UM BOLO” E “FAZER UM DESENHO”}

Nesta parte, examinamos um conjunto de materiais considerados para o ensino de frações que fizeram parte das práticas para a formação 
dos professores de matemática da década de 1970. Na Figura 1, tomamos um recorte, parte do caderno de planejamento, em que a professora de Didática da Matemática encaminhava as "Frações Ordinárias", considerando a significação, o aspecto didático, as operações, as frações mais usadas na vida, a necessidade do uso do material concreto e a definição de fração.

Figura l - Frações ordinárias

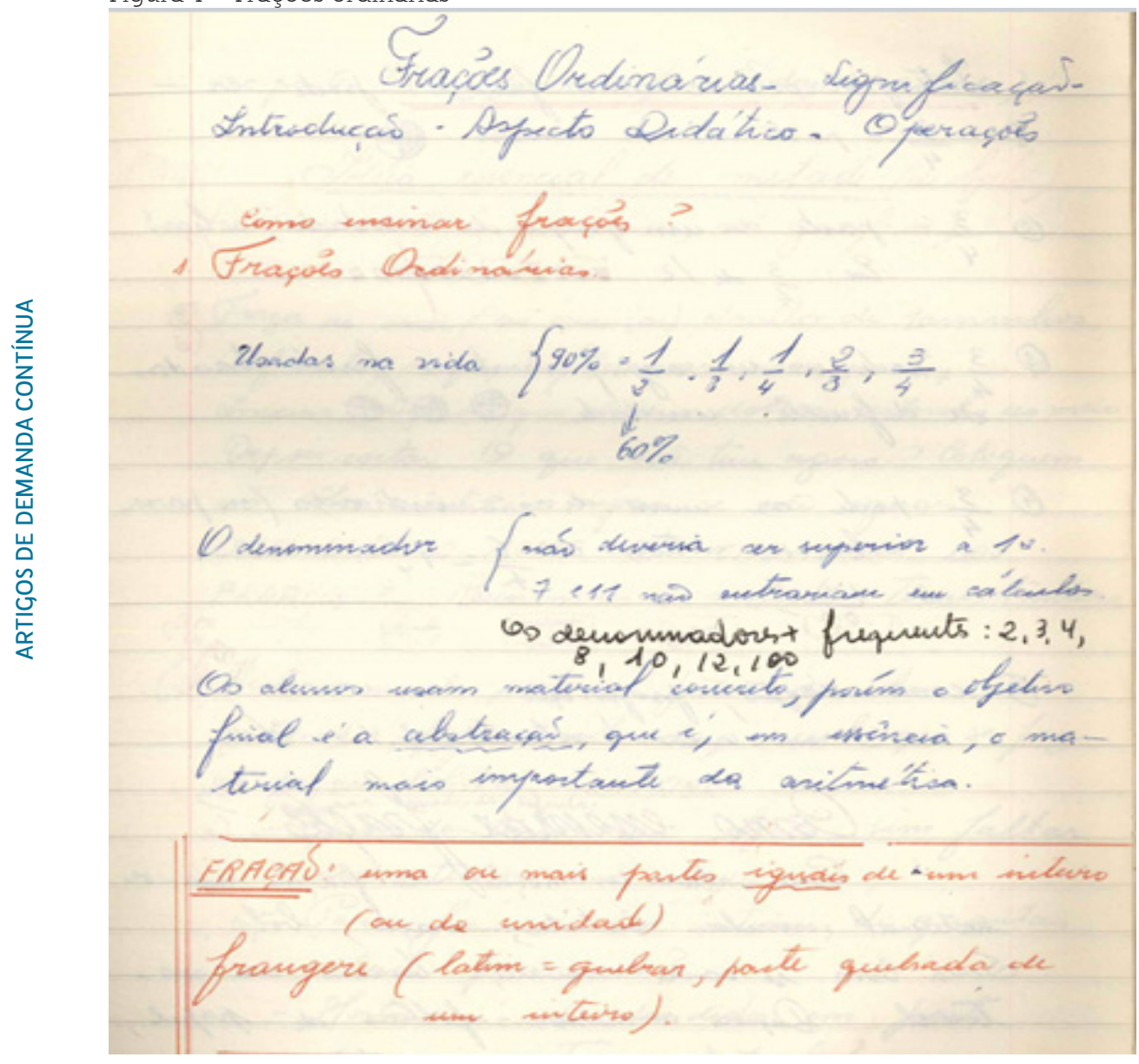


Legenda: Frações Ordinárias - Significações - Introdução - Aspecto didático - Operações Como ensinar frações?

1. Frações Ordinárias

a. Usadas na vida $\{90 \% \times 1 / 2 \times 1 / 3 \times 1 / 4 \times 2 / 3 \times 3 / 4$

$60 \%$

O denominador \{não deveria ser superior a 18. 7 e 11 não entrariam em cálculos

Os denominadores mais frequentes: $2,3,4,8,10,12,100$

Fração: uma ou mais partes iguais de um inteiro (ou da unidade)

Fraugere (latim = quebrar, parte quebrada de um inteiro).

Fonte: caderno de planejamento (informação verbal).

Na continuação do caderno de planejamento, destacamos alguns recortes que mostram como ensinar frações, a partir de materiais concretos, qual a sequência a ser seguida e os principais questionamentos. Percebe-se que, para ensinar frações, alguns passos ou etapas são organizados: a) uso do material concreto; b) representação de frações usando desenhos; c) exploração de materiais, como círculos, quadrados e retângulos; e d) conclusão: retomada de todas as ideias desenvolvidas desde o início da exploração da "noção de fração", como consta no caderno de planejamento. 
Figura 2 - Como ensinar frações?

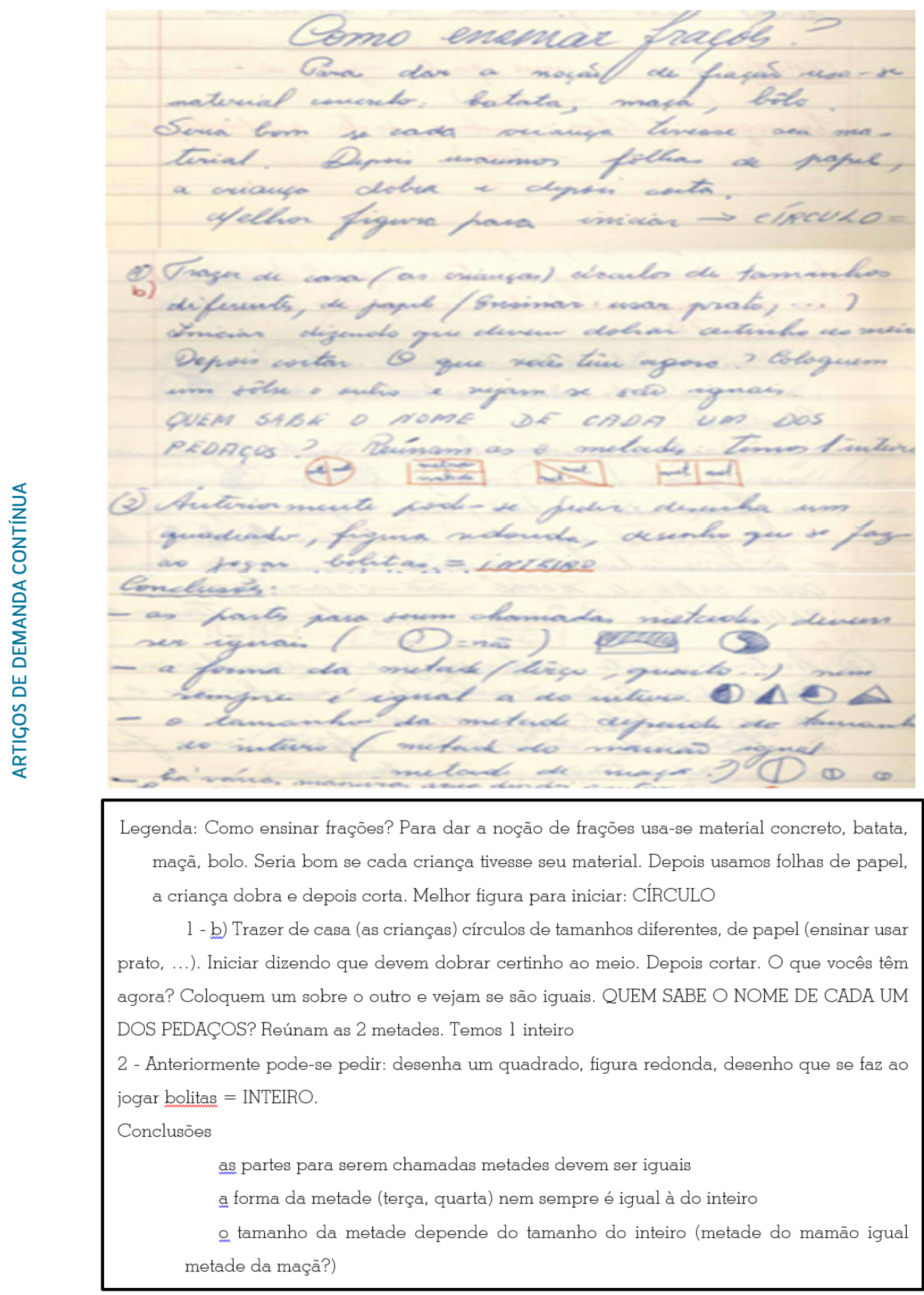

Fonte: caderno de planejamento (informação verbal). 
Observa-se, nesse material, uma sequência didática que suspeitamos ter levado os professores a acreditarem que, para aprender fração, o aluno precisava manusear e observar objetos concretos, descrever e desenhar. Nesse exemplo, a professora salienta que "a criança nem sempre tem o sentido real do que seja metade: 'eu quero a metade maior?' ." Então, caberia ao professor, a partir de questionamentos, "fazer" com que os alunos percebessem o que é o inteiro e o que é a metade, desenhando e comparando tamanhos. Aebli (1978, p. 11 ) considera que, para ensinar tal "noção", por exemplo, o professor ultrapassa as fronteiras de um método intuitivo, de imagens mentais apenas, que estariam colocadas nos sentidos, fazendo uso de outros materiais que não "decorrem, de maneira alguma, da psicologia sensualista-empirista"; o professor precisa propor atividades que, mesmo sendo mais ativas, continuam em uma perspectiva que parte da intuição para chegar à abstração.

A partir de Aebli (1978), discutimos que o ensino de frações estava relacionado à lógica da psicologia do desenvolvimento, que tem produzido práticas matemáticas associadas a movimentos ou tendências empíricoativistas. Esse ideário que considera o desenvolvimento natural da criança e se ancora nos estudos da biologia e da psicologia, conforme Fiorentini (1995), apesar da intenção de romper com a "concepção idealista de conhecimento", com a "escola clássica tradicional", nas primeiras décadas do século XX, com o "fracasso provocado pelo formalismo modernista", só na década de 1970 provocou o envolvimento de grupos de professores ligados à Matemática.

Juntamente com essas ideias, começam a aparecer algumas perspectivas construtivistas, segundo Miguel e Vilela (2008), sendo uma delas a perspectiva piagetiana, que faz crítica ao ensino baseado em práticas empíricointuitivas, enfatizando a ideia da ação e da operação. "A operação constitui o elemento ativo do pensamento. É ela que assegura os progressos essenciais da inteligência, em oposição à imagem, que desempenha o papel de elemento estático [...]" (AEBLI, 1978, p. 51).

Esses encaminhamentos levam-nos a pressupor que exista uma matemática a ser descoberta, um conceito matemático que precisa ser aprendido a partir de uma relação com um ente ideal. Em perspectivas empiristas, que são herdeiras de algumas ideias, como o logicismo e o formalismo, acredita-se, de 
acordo com Barker (1969 apud GOTTSCHALK, 2014, p. 75), que existiriam dois tipos de conhecimento: "o empírico e o a priori. Áreas como a física, a biologia e a história assentam suas conclusões em observações (conhecimento empírico), enquanto uma matéria como a lógica busca obter conhecimento a priori das regras que governam a validade dos argumentos."

As ideias herdeiras das perspectivas empiristas parecem ter produzido os encaminhamentos com o ensino de frações ainda nos tempos atuais. Encontramo-las em materiais organizados para a formação continuada de professores, como o caderno Pró-Letramento: Programa de Formação Continuada de Professores dos Anos/Séries Iniciais do Ensino Fundamental: matemática (BRASIL, 2007). Nesse documento - o primeiro analisado produzido pelo Governo Federal para a formação continuada de professores dos anos iniciais, propõe-se um curso, organizado em fascículos, como Números Naturais, Operações com Números Naturais, Espaço e Forma, Frações, Grandezas e Medidas, Tratamento da Informação, Resolver problemas: o lado lúdico do ensino da Matemática e Avaliação da Aprendizagem em Matemática nos Anos Iniciais. $\bigcirc$ fascículo Frações é apresentado de modo diferente dos demais, como dito no material, pois "o tema das frações costuma apresentar uma dificuldade maior, do ponto de vista do conteúdo, do que os outros temas"; por isso, aponta-se "a importância de representar uma situação de várias maneiras". Sugere-se usar a ideia de repartir um bolo e de "mostrar", a partir de desenhos, a representação de metade do bolo e a sua relação com a sua massa (quilos), o que apresentamos na Figura 3. 
Figura 3 - Repartir um bolo

As frações $\frac{1}{2}$ e $\frac{2}{4}$ são equivalentes; tanto faz repartir um bolo em duas partes e pegar uma, quanto repartir o mesmo bolo em quatro partes e pegar duas.

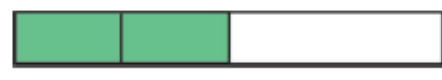

É, no entanto, muito importante, quando resolvemos problemas, prestar bastante atenção: se a fração $\frac{1}{2}$ se refere a um bolo e a fração $\frac{2}{4}$ se refere a outro, não faz sentido comparar as duas frações em relação à quantidade de bolo. Metade de um bolo de oito quilos é quatro quilos, enquanto $\frac{2}{4}$ de um bolo de um quilo é meio quilo de bolo!
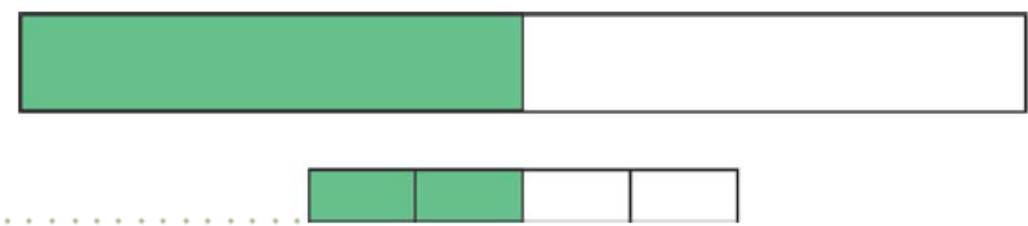

O que podemos dizer, no entanto, é que a razão entre o bolo todo e a parte comida é a mesma nos dois casos. Comparando razões podemos determinar se o que se comeu do primeiro bolo é proporcional ao que se comeu do segundo, isto é, estamos comparando relações, e não quantidades.

Fonte: Brasil (2007, p. 17).

Como afirma Gottschalk (2004, p. 307), o ensino da matemática em uma perspectiva experimental concebe a existência de "um mundo de experiências a ser compartilhado, que revelaria uma realidade matemática a ser observada e descoberta", ou melhor, uma "concepção empirista da matemática." Mesmo que as práticas pedagógicas sejam tomadas de uma perspectiva experimental ou de uma perspectiva construtivista, em que o aluno é levado a construir o conhecimento a partir do slogan é o aluno que constrói seu próprio conhecimento, concordamos com a autora que não é "possível alcançar qualquer conhecimento, inclusive o matemático, por si só, bastando para isto que sejam propiciadas condições suficientes de aprendizagem." (GOTTSCHALK, 2014, p. 74). É necessário que o professor apresente modelos, ensine a lidar com as regras matemáticas, pois, como exemplifica Hebeche (2002, p. 196), 
[o] cálculo de cabeça (ou no papel) coincide com a práxis de seguir a regra, por isso não é uma atividade mental, mas o domínio de uma técnica [...], não se pode explicar, de modo transcendental ou pela psicofisiologia, a atividade de calcular, sem que já se sigam as regras de multiplicação e divisão.

Em consonância com as ideias de Wittgenstein (1979), Gottschalk (2004, p. 313) considera que "[a]s proposições matemáticas institucionalizadas é que dão sentido à atividade matemática, e não que sejam geradas por ela, através de processos empíricos (mentais ou consensuais)." As proposições matemáticas são convenções que pertencem a um grupo, a uma comunidade; fazem parte de acordos públicos, estabelecidos em concordância com as formas de vida, o que nem sempre fica explicitado, mas sempre faz parte de uma gramática compartilhada pelo grupo.

Para continuar essa discussão, aproveitamos o que ensina Wittgenstein (1978) (\$37, 38) em Observaciones sobre los fundamentos de la matemática. As crianças aprendem a calcular a partir da contagem de objetos; colocando, por exemplo, duas maçãs e acrescentando mais duas, o resultado será, provavelmente, quatro. Porém, se usássemos outros materiais, e houvesse, uma vez, um resultado, outra vez, outro, diríamos que os materiais são inadequados para o ensino do cálculo. $\bigcirc$ filósofo questiona: "não seria $2+2=4$ ?" (WITTGENSTEIN, 1978, p. 31). $O$ que podemos pensar sobre isso? Que uma proposição matemática "não é negada nem confirmada, é apenas uma regra de como proceder" (GOTTSCHALK, 2008, p. 79) em que, se temos duas maçãs sobre uma mesa e colocarmos mais duas, teremos quatro maçãs. Existe uma regra que organiza a aceitação pelos membros que participam da comunidade, e a "seguimos independentemente do que ocorra de fato." (GOTTSCHALK, 2008, p. 80).

Assim, isso difere de uma perspectiva de ensino em que a descoberta é desencadeadora das atividades matemáticas, como, por exemplo, a perspectiva empírico-intuitiva do matemático Poincaré e de outros matemáticos, que acreditavam que os objetos matemáticos deveriam ser descobertos. Com as contribuições do segundo Wittgenstein, entendemos, junto com Bello (2010), Vilela (2007, 2010, 2013) e Miguel, Vilela e Moura (2012), que a matemática é 
uma prática social regrada. Mais ainda, percebemos que "para sua transmissão e construção seja fundamental o ensino de técnicas e de procedimentos que foram inventados pelos matemáticos ao longo dos tempos, e não descobertos como sugerem as práticas pedagógicas atuais." (GOTTSCHALK, 2008, p. 93, grifo do autor).

\section{2 "LEMBRAR SEU SIGNIFICADO" PARA ENSINAR FRAÇÕES}

No terceiro documento examinado, trazemos a transcrição de uma conversa em que a professora de Didática da Matemática questiona as alunas sobre o ensino de frações e explica a necessidade da retomada dos conceitos matemáticos, de "lembrar seu significado", pois, como aponta, há necessidade de estudar o conceito. $\bigcirc$ registro dessa conversa está presente no diário de campo e faz parte do material de pesquisa realizada pela primeira autora do artigo (POZZOBON, 2012).

Como é que tu vais ensinar uma fração para uma criança? $\bigcirc$ que tu vais fazer? "Ah, vou trazer um bolo, ah, eu vou fazer um desenho, ah...". Então, trazer a contribuição da turma. Tinha muito isso. Como os conteúdos das séries iniciais só foram praticamente vistos no primeiro grau, as alunas tratavam mecanicamente os conteúdos. Somavam, dividiam, calculavam área sem saber ou lembrar seu significado. É aí que eu quero dizer o seguinte: as alunas do segundo grau, quando é que elas estudaram os conceitos básicos, a soma, a subtração, a divisão? Elas estudaram lá no primeiro, segundo, terceiro, quarto ano. Depois, esse conteúdo, [que] já era um alicerce dos próximos conteúdos matemáticos, nunca mais foi retomado. Então, eles estavam mecanizados, mas só com a mecânica das coisas tu não podes dar uma aula para uma criança. Então, aí que elas diziam que estavam aprendendo os conceitos. "Agora estou aprendendo os conceitos, professora!" (Professora de Didática da Matemática, informação verbal).

Diante desse excerto, cabe questionar: como se ensina o conceito de fração? A partir de vivências com o uso de materiais, de observações, de 
descobertas, de situações cotidianas? Com base em Wittgenstein, Hebeche (2003) pode nos ajudar a pensar sobre essas questões e, principalmente, sobre o ensino de matemática em que a ênfase está em ensinar frações para os futuros professores, pois, como alertava a professora de Didática da Matemática: "[...] frações, não é? Frações é... Era uma coisa que meio aterrorizava as gurias." (informação verbal). Para aquele autor, a compreensão não está determinada pela definição ou pela explicação, mas é uma técnica, um modo de seguir regras aprendidas, por isso não é um processo mental, individual, que está guardado na memória, pronto para ser manifestado pela linguagem. Com essas ideias, é possível pensarmos na significação das atividades matemáticas a partir das discussões de Wittgenstein (1979), que diferem das proposições empíricas, mentais e abstratas, uma vez que "[...] a linguagem matemática não descreve a realidade empírica (embora possa ser usada para descrevê-la), não descreve objetos concretos, nem abstratos, nem mentais [...]" (SILVA, 201 l, p. 55).

Para dar continuidade ao que mostramos anteriormente, consideramos o dito pela professora ao apontar que talvez a dificuldade estivesse na própria disciplina e que as alunas soubessem pouca matemática.

[...] elas tinham um conceito geral de toda a Matemática. Elas tinham. Isso elas sabiam. Tinham vivências de todo o conteúdo para séries iniciais, como introduzir esses conceitos, obedecendo à graduação de dificuldades, com experiência de planos de aula. Sempre os planos de aula. A maior dificuldade talvez estivesse na dificuldade da própria disciplina. [...] Vamos ver, na dificuldade da disciplina, isso aqui, que as gurias sabiam muito pouca Matemática. Elas sabiam pouco, como conteúdo, não como didática da Matemática. Como elas sabiam pouco conteúdo, digamos, pouco conteúdo de frações, elas não manipulavam frações, assim, elas não tinham aquela capacidade de aproveitar situações e introduzir algum conceito de fração ali porque elas não tinham o conceito. (Professora de Didática da Matemática, informação verbal).

Nessa fala, a professora diz que, em decorrência de saberem "pouco conteúdo", as alunas apresentavam dificuldades em desenvolver planos de 
aula que promovessem a "manipulação de frações" e, consequentemente, a proposição de situações para introduzir o conceito. Isso, por um lado, mostra uma preocupação bastante pertinente com as aprendizagens ou com as aprendizagens para ensinar matemática nos anos iniciais; por outro lado, ao considerar-se a "manipulação" das frações, há um apego às ideias que aproximavam a matemática das ciências empíricas, como nos alerta Gottschalk (2014), produzindo "confusões" e "repercussões" na prática escolar, ancoradas na concepção referencial de linguagem. Contrapondo-se a essas ideias, Wittgenstein (1979) diz que não existe nada a ser descoberto, pois a "significação de uma palavra é seu uso na linguagem." Essas ideias ficam evidenciadas ao considerar:

Que significa quando digo, por exemplo: este número pode obter-se da multiplicação daqueles dois? Trata-se de uma regra que diz que temos de obter este número necessariamente se multiplicarmos corretamente; e essa regra podemos obter multiplicando ambos os números [...] Diz-se, então, que tem multiplicado quando tenha realizado a multiplicação 265 x 463, porém também quando digo: "4 por 2 são 8", apesar de que neste caso nenhum procedimento de cálculo foi levado até o produto (que eu poderia ter calculado). E assim é como dizemos também que obtém uma conclusão quando não se calcula. (WITTGENSTEIN, 1978, p. 20, tradução nossa).

Com esses esclarecimentos, é possível estabelecer algumas relações entre os jogos de linguagem e a aprendizagem de conceitos matemáticos, que se aproximam pelas regras de constituição, pelas semelhanças, pelos parentescos. Para Silveira (2008, p. 94), "os jogos de linguagem apresentam as semelhanças entre jogos e linguagem, assim como o cálculo ressalta as semelhanças existentes entre linguagem e sistemas formais." Tais ideias estão de acordo com o dito por Wittgenstein (1979) ao se referir aos jogos de linguagem "como um método para mostrar os diferentes usos dos conceitos em nossas formas de vida." Para o autor, as palavras adquirem significado nos jogos de linguagem, na operacionalização, nos usos que fazemos dos conceitos, o que nos permite dizer que os "jogos de linguagem constituem as relações de 
significação básica (denominação) e são, portanto, os elos entre linguagem e realidade." (GOTTSCHALK, 2014, p. 79).

Tendo em vista esses argumentos, no Pró-Letramento, no fascículo 4, encontramos algumas orientações na seção E para que serve comparar frações. Nessa seção, são propostos alguns exemplos de "aplicabilidade" do conceito de frações, por exemplo: "Suponha que na cidade A, 3 de cada 4 casas têm telefone, enquanto que na cidade B, 2 de cada 3 casas têm telefone. Qual delas está mais bem equipada em termos de telefonia?" (BRASIL, 2007, p. 28). Na continuação, discute-se que, se não há o número de casas em cada cidade, é possível resolver a questão a partir da comparação de frações, da ideia de razão, como destacamos na Figura 4.

Figura 4 - Comparando frações

Para responder a esta pergunta, não precisamos saber quantas casas há em cada uma das cidades; o que vamos considerar é a razão entre número de casas com telefones e número total de casas, e podemos fazer isto comparando as frações $\frac{3}{4}$ e $\frac{2}{3}$. Feita a comparação, veremos que $\frac{3}{4}$ é maior que $\frac{2}{3}$, o que indica que a cidade A está mais bem servida de telefonia. Se você usar a técnica que usamos até aqui, que é achar frações equivalentes às duas, e com mesmo denominador, vai encontrar que

$$
\frac{3}{4}=\frac{9}{12} \quad \text { e } \frac{2}{3}=\frac{8}{12}
$$

Fonte: Brasil (2007, p. 28).

É importante considerar que as proposições matemáticas são compreendidas "como regras a serem seguidas", mas "não descrevem entidades abstratas, nem a realidade empírica"; elas são normativas, "paradigmas para a transformação de proposições". Isso quer dizer que as proposições matemáticas podem ter um uso empírico, mas não se referirem aos objetos (GOTTSCHALK, 2014, p. 80). Para Wittgenstein (1979), "não existiriam significados de número racional, ou de outro número qualquer, como o irracional, imaginário, para os quais o aluno tenderia paulatinamente a ir resolvendo determinadas situações problemáticas" (GOTTSCHALK, 2008, p. 85), mas o que mostra cada situação é um contexto diferente de uso dos números, com suas regras, sua gramática de 
funcionamento. Pontuamos que, na perspectiva de "contextualizar" a situação proposta, no Pró-Letramento, explicam-se os resultados encontrados usandose a comparação de frações, que levaram à seguinte resposta:

$$
\frac{3}{4}=\frac{9}{12} \frac{3}{4}=\frac{9}{12} \frac{2}{3}=\frac{8}{12} \frac{2}{3}=\frac{8}{12}
$$

"Isto é, se visitarmos 12 casas da cidade A, escolhidas ao acaso, é provável que 9 delas tenham telefone, enquanto que de 12 casas da cidade B, apenas 8 teriam telefone." (BRASIL, 2007, p. 28).

A partir de tal exemplo, salientamos a necessidade de tomarmos alguns cuidados em relação aos usos nos diferentes contextos. Se existem outros modos de ensinar o conceito de fração, acreditamos que pode ser a partir dos usos em que o "número racional", a fração passa a ter "sentido dentro de um jogo de linguagem." Dessa forma, os contextos podem colaborar para contemplar diferentes significados para a aprendizagem do conceito de fração, uma vez que as proposições matemáticas têm um caráter semelhante ao de um jogo de linguagem, afastando-se dos objetos empíricos, mas também se aproximando do mundo empírico pelas suas aplicações (GOTTSCHALK, 2014). Para que isso aconteça, há necessidade de conhecimento, por parte do professor, a respeito da natureza das proposições matemáticas e da sua responsabilidade diante do ensino de modelos que sirvam para o uso na "práxis da linguagem." (WITTGENSTEIN, 1979).

A partir disso, lembramos de uma situação vivenciada em sala de aula por um de nós, em que uma aluna do Curso de Pedagogia de uma instituição privada do Rio Grande do Sul sabia operar 2/3 + 1/3 a partir do uso do chocolate e do bolo. No entanto, ao ser-lhe colocada a pergunta: quantos ovos devo adicionar em uma receita quando indicar 1/3 de uma dúzia? A aluna não conseguia fazer o registro correto. Essa lembrança nos faz tencionar se houve a aprendizagem do conceito de fração, ou seja, se a aluna aprendeu as "[...] regras e procedimentos matemáticos públicos [...] portanto não basta contextualizar a matemática e valorizar o conhecimento do aluno, uma vez que para diferentes tipos de cálculos são necessárias diferentes técnicas." (SILVEIRA; 
SILVA, 2016, p. 471). Desse modo, em consonância com Wittgenstein (1979), consideramos que os conceitos são normas que independem do cotidiano e de aspectos empíricos, intuitivos ou indutivos.

\section{ALGUMAS CONSIDERAÇÕES}

Para encaminhar as considerações finais do presente artigo, voltamos às intenções iniciais, ou seja, pensar sobre como a formação do professor que ensina matemática nos anos iniciais constitui modos de ser e de agir para o ensino de frações. No artigo discutiu-se sobre a formação do professor que ensina matemática nos anos iniciais, em especial no que se refere ao ensino de frações. Conforme referido anteriormente, o corpus de análise se constituiu de um caderno de planejamento de uma professora de Didática da Matemática, do caderno Pró-Letramento: Programa de Formação Continuada de Professores dos Anos/Séries Iniciais do Ensino Fundamental: matemática (BRASIL, 2007) e de uma entrevista com a mesma professora. $\bigcirc$ escrutínio do material de pesquisa foi realizado a partir de uma perspectiva teórica pós-crítica (VILELA, 2013). Das análises empreendidas, emergiram dois enunciados: a) Ensinar frações: "trazer um bolo" e "fazer um desenho" e b) "Lembrar seu significado" para ensinar o conceito de frações.

De modo geral, partimos do pressuposto de que o conhecimento matemático produz as práticas e os sujeitos pedagógicos; assim, entendemos que os conceitos são produzidos a partir dos usos, em conformidade com suas regras gramaticais. Cada professor é convidado a participar de práticas de formação que o (de)formam e ao mesmo tempo o constituem enquanto professor que ensina matemática nos anos iniciais do Ensino Fundamental. Dessa maneira, ao tratarmos da formação de professores que ensina matemática para o ensino de frações, chamamos atenção para alguns cuidados.

$\bigcirc$ primeiro deles é alertar para a impossibilidade de realizar a transferência do uso das frações de um contexto para outro, e que apenas podemos estabelecer aproximações entre os usos. Nesse sentido, a Matemática, 
como componente curricular, não pode ser apresentada somente como um conjunto de conhecimentos a ser aplicado e utilizado pelo aluno.

O segundo é que, na formação do docente que vai ensinar matemática, faz-se necessário que os diferentes usos das frações em diferentes contextos sejam percebidos no sentido de romper com uma abordagem internalista da matemática, voltada somente aos conceitos. Nos materiais examinados e no cotejamento com documentos mais recentes foi isso que encontramos. Suspeitamos, então, que uma mesma matemática, centrada no formalismo, constitui-se como teoria hegemônica que informa o professor ainda nos dias atuais.

Isso não quer dizer que defendemos que as práticas de ensino de matemática deixem de lado práticas pedagógicas já consolidadas que fazem uso do material concreto e de situações com referência ao cotidiano. Pelo contrário, sugerimos que as diferentes técnicas sobre o uso de frações sejam tratadas na formação de professores. No entanto, destacamos os signos matemáticos conforme Wittgenstein (1979); ou seja, o signo não tem em si o seu sentido, mas os sentidos são produzidos nos usos, conforme discutido neste artigo.

Por fim, perguntamo-nos: será que continuamos a ensinar frações com a mesma ênfase da década de 1970?

\section{REFERÊNCIAS}

AEBLI, H. Didática psicológica: aplicação à didática da psicologia de Jean Piaget. São Paulo: Nacional, 1978.

BELLO, S. E. L. Jogos de linguagem, práticas discursivas e produção de verdade: contribuições para a educação (matemática) contemporânea. Revista Zetetiké, Unicamp, v. 18, 2010. Número temático.

BRASIL. Pró-Letramento: Programa de Formação Continuada de Professores dos Anos/Séries Iniciais do Ensino Fundamental: matemática. Fascículo 4. Brasília, DF: Ministério da Educação, Secretaria de Educação Básica, 2007.

COUTINHO, K. D.; SOMMER, L. H. Discursos sobre a formação de professores e arte de governar. Currículo sem Fronteiras, v. 11, n. 1, p. 86-103, jan./jun. 2011. 
DÍAZ, M. Foucault, docentes e discursos pedagógicos. In: SILVA, T. T. (Org.). Liberdades reguladas: a pedagogia construtivista e outras formas de governo do eu. Petrópolis: Vozes, 1998.

FABRIS, E. T. H. A relação universidade e escola de educação básica na produção da docência contemporânea. Relatório de pesquisa. Financiado pelo CNPg/Unisinos. 2012.

FIORENTINI, D. Alguns modos de ver e conceber o ensino da Matemática no Brasil. Revista Zetetiké, ano 3, n. 4, 1995.

FOUCAULT, M. Arqueologia do saber. Rio de Janeiro: Forense Universitária, 2007.

FOUCAULT, M. Diálogo sobre o poder. In: FOUCAULT, M. (Org.). Estratégia, poder-saber. Rio de Janeiro: Forense Universitária, 2003.

FOUCAULT, M. Do governo dos vivos. Curso no Collège de France, 19791980 (excertos). São Paulo: CCS; Rio de Janeiro: Achiamé, 2010.

GLOCK, H. Dicionário Wittgenstein. Tradução Helena Martins. Rio de Janeiro: Jorge Zahar, 1998.

GOTTSCHALK, C. M. C. A construção e transmissão do conhecimento matemático sob uma perspectiva Wittgensteiniana. Cadernos Cedes, Campinas, v. 28, n. 74, p. 75-96, jan./abr. 2008. Disponível em: <http://www.cedes. unicamp.br>. Acesso em: 20 jun. 2009.

GOTTSCHALK, C. M. C. A natureza do conhecimento matemático sob a perspectiva de Wittgenstein: algumas implicações educacionais. Cadernos de História e Filosofia da Ciência, Campinas, série 3, v. 14, n. 2, p. 305-334, jul./dez. 2004.

GOTTSCHALK, C. M. C. Fundamentos filosóficos da matemática e seus reflexos no contexto escolar. International Studies on Law and Education. CEMOrOc-Feusp/IJI-Uni. Do Porto, set./dez. 2014. Disponível em: $<$ http://www.hottopos.com/isle 18/73-82Cristiane.pdf>. Acesso em: 02 abr. 2014.

GOTTSCHALK, C. M. C. O papel da linguagem no ensino e na aprendizagem da perspectiva de uma pragmática filosófica de inspiração wittgensteiniana. In: ANPED, 28., 2005, Caxambu. Anais... Caxambu, 2005. Disponível em: <www.28reuniao.anped.org.br/textos/gtl 7/gtl 7362int.rtf>. Acesso em: 20 jun. 2009. 
GOTTSCHALK, C. M. C. Uma concepção pragmática de ensino e aprendizagem. Educação e Pesquisa, São Paulo, v. 33, n. 3, p. 459-470, set./dez. 2007.

HEBECHE, L. O mundo da consciência: ensaio da filosofia da psicologia L. Wittgenstein. Porto Alegre: EDIPUCRS, 2002.

HEBECHE, L. Não pense, veja - sobre a noção de "semelhanças de família" e Wittgenstein. Veritas, v. 48, n. 1, p. 31-58, 2003.

LAVE, J. Do lado de fora do supermercado. In: FERREIRA LEAL, M. (Org.). Ideias matemáticas de povos culturalmente distintos. São Paulo: Global, 2002 .

MIGUEL, A.; VILELA, D. S.; MOURA, A. R. L. de. Problematização indisciplinar de uma prática cultural numa perspectiva wittgensteiniana. Revista Reflexão e Ação, Santa Cruz do Sul, v. 20, n. 2, p. 6-32, jul./dez. 2012.

MIGUEL, A.; VILELA, D. S. Práticas escolares de mobilização de cultura matemática. Cadernos Cedes, Campinas, v. 28, n. 74, p. 97-120, jan./abr. 2008.

MORENO, A. R. Wittgenstein - através das imagens. Campinas: Ed. Unicamp, 1995.

POZZOBON, M. C. C. Práticas de ensino de Matemática: regimes e jogos na formação do professor de anos iniciais (1960-2000). 2012. Tese (Doutorado em Educação)_Universidade do Vale do Rio dos Sinos, São Leopoldo, 2012.

SILVA, P. V. da. O aprendizado das regras matemáticas: uma pesquisa de inspiração wittgensteiniana com crianças da $4^{a}$ série no estudo da divisão. 201 l. 102 p. Dissertação (Mestrado em Educação em Ciências e Matemáticas)-Universidade Federal do Pará, Pará, 2011.

SILVA, P. V. da; SILVEIRA, M. R. A. da. Matemáticas ou diferentes usos da matemática? Reflexões a partir da filosofia de Wittgenstein. Acta Scientiarum Education, Maringá, v. 35, n. 1, p. 125-132, jan./jun. 2013.

SILVEIRA, M. R. A. da. Aplicação e interpretação de regras matemáticas. Educação Matemática Pesquisa, São Paulo, v. la, n. 1, p. 93-1 13, 2008.

SILVEIRA, M. R. A. da; SILVA, P. V. da. O cálculo e a escrita matemática na perspectiva da filosofia da linguagem: domínio de técnicas. Educação Matemática Pesquisa, São Paulo, v. 18, n. 1, p. 469-483, 2016.

VEIGA-NETO, A. Foucault \& a Educação. Belo Horizonte: Autêntica, 2007. 
VILELA, D. S. A terapia filosofia de Wittgenstein e a educação matemática. Educação e Filosofia, Uberlândia, v. 24, n. 48, jul./dez. 2010.

VILELA, D. S. Matemática nos usos e jogos de linguagem: ampliando concepções na Educação Matemática. 2007. 260 p. Tese (Doutorado em Educação)-Universidade Estadual de Campinas, Campinas, 2007.

VILELA, D. S. Usos e jogos de linguagem na matemática: diálogo entre filosofia e educação matemática. São Paulo: Livraria da Física, 2013.

WITTGENSTEIN, L. Investigações Filosóficas. São Paulo: Abril Cultural, 1979.

WITTGENSTEIN, L. Observaciones sobre los fundamentos de la matemática. Madrid: Alianza Editorial, 1978.

Recebido em 13 de outubro de 2017

Aceito em 15 de agosto de 2018

Endereços para correspondência: Rua General Argolo, 1418, Apto. 201, 96015-160, Pelotas, Rio Grande do Sul, Brasil; marta.pozzobon@hotmail.com 